\title{
Use of Quantitative Traits to Assess Aggressiveness of Phakopsora pachyrhizi Isolates from Nigeria and the United States
}

M. Twizeyimana, Department of Crop Sciences, University of Illinois, Urbana, IL 61801; P. S. Ojiambo, Department of Plant Pathology, North Carolina State University, Raleigh, NC 27695; R. Bandyopadhyay, International Institute of Tropical Agriculture, Ibadan, Nigeria; and G. L. Hartman, United States Department of Agriculture-Agricultural Research Service, and Department of Crop Sciences, University of Illinois, Urbana, IL 61801

\begin{abstract}
Twizeyimana, M., Ojiambo, P. S., Bandyopadhyay, R., and Hartman, G. L. 2014. Use of quantitative traits to assess aggressiveness of Phakopsora pachyrhizi isolates from Nigeria and the United States. Plant Dis. 98:1261-1266.

Soybean rust, caused by Phakopsora pachyrhizi, is one of the most important foliar diseases of soybean worldwide. The soybean-P. pachyrhizi interaction is often complex due to genetic variability in host and pathogen genotypes. In a compatible reaction, soybean genotypes produce tan-colored lesions, whereas in an incompatible reaction soybean genotypes produce an immune response (complete resistance) or reddish-brown lesions (incomplete resistance). In this study, in total, 116 and 72 isolates of $P$. pachyrhizi from Nigeria and the United States, respectively, were compared based on six quantitative traits to assess their aggressiveness on two soybean genotypes. All isolates produced reddish-brown lesions on plant introduction (PI) 462312 and tan lesions on TGx 1485-1D. The number of days after inoculation to first appearance of lesions, uredinia, and sporulation, along with the number of lesions and sporulating uredinia per square centimeter of leaf tissue, and the number of uredinia per lesion, were significantly $(P$ $<0.001)$ different between the two soybean genotypes for all isolates

from each country. The number of days to first appearance of lesions, uredinia, and sporulation were greater on PI 462312 than on TGx 1485-1D for all the test isolates. Similarly, the number of lesions and sporulating uredinia per square centimeter, and the number of uredinia per lesion were lower on PI 462312 than on TGx 1485-1D. For both soybean genotypes, the number of sporulating uredinia per square centimeter significantly $(P=0.0001)$ increased with an increase in the number of lesions per square centimeter. Although the slope of the regression of sporulating uredinia on number of lesions was greater $(P$ $<0.0001$ ) when TGx 1485-1D was inoculated with Nigerian isolates compared with U.S. isolates, slopes of the regression lines did not differ significantly $(P>0.0675)$ when PI 46312 was inoculated with Nigerian or U.S. isolates. This is the first study that used a large number of isolates from two continents to assess aggressiveness of $P$. pachyrhizi using multiple traits in soybean genotypes with contrasting types of disease reaction.
\end{abstract}

Soybean rust, caused by Phakopsora pachyrhizi Syd., is one of the most important diseases of soybean worldwide. Yield losses result from severe infection, defoliation, and premature maturation (8). Soybean rust can be managed with fungicides $(12,18,20)$ and, partially, by some cultural practices; for example, the use of resistant cultivars (7) and, if possible, alteration of planting dates (28).

Three infection types have been used to describe the soybean- $P$. pachyrhizi interaction: (i) type 0 , immune, with no visible infection; (ii) type RB, red-brown lesions, with either no uredinia or only sparsely sporulating uredinia; and (iii) type TAN, tan lesions, usually with many uredinia and abundant sporulation (3). These infection types have been used to describe the genetics of soybean resistance to $P$. pachyrhizi and to describe virulence differences among $P$. pachyrhizi isolates on soybean accessions with known

Corresponding author: G. L. Hartman, E-mail: ghartman@illinois.edu

Current address of M. Twizeyimana: AgBiome, Inc., Research Triangle Park, NC 27709.

Trade and manufacturers' names are necessary to report factually on available data; however, the United States Department of Agriculture (USDA) neither guarantees nor warrants the standard of the product, and the use of the name by USDA implies no approval of the product to the exclusion of others that may also be suitable.

Accepted for publication 28 March 2014.

http://dx.doi.org/10.1094/PDIS-12-13-1247-RE

This article is in the public domain and not copyrightable. It may be freely reprinted with customary crediting of the source. The American Phytopathological Society, 2014. resistant genes. The soybean- $P$. pachyrhizi interaction has been reviewed in depth elsewhere (7). Briefly, isolate differences were first recognized in Taiwan in 1966 (15) and further differentiated in Australia (4,5,16), Japan (33), the United States-based on imported isolates before the 2004 introduction into the United States (3) and after the 2004 introduction $(2,24,27)$ - and Nigeria (30). Most of these reports differentiated isolates based on virulence records of compatible and incompatible reactions. In addition to qualitative assessment of the soybean- $P$. pachyrhizi interaction, a quantitative assessment of this interaction (e.g., aggressiveness) may be obtained by recording the degree of host damage or pathogen multiplication in the host $(1,21,31)$. In a recent review article, Pariaud et el. (21) defined aggressiveness, provided its historical use, and defined the components or traits that can be used to measure aggressiveness. A number of reports have documented aggressiveness in rust fungi, including Puccinia striiformis f. sp. tritici (19) and P. triticina (22), as well as in other fungal soybean pathogens, including species of Fusarium $(6,14)$ and Phomopsis $(13)$ and Sclerotinia sclerotiorum (10).

The earliest study to show differences in aggressiveness among $P$. pachyrhizi isolates was reported in 1979, when cultures of $P$. pachyrhizi from Australia, India, Indonesia, and Taiwan were shown to differ in colonization rates and urediniospore production on plants of susceptible 'Wayne' soybean (17). In a similar study, aggressiveness among $P$. pachyrhizi isolates collected from Australia, India, Puerto Rico, and Taiwan were shown to differ in the amount of lesion area produced and the number of uredinia per lesion (3). More recent studies have focused on isolates from recent introductions in Nigeria and the United States and have taken similar measurements, including the number of uredinia per lesion or uredinia per unit of leaf tissue, to quantify differences among isolates representing different geographic and temporal origins $(2,23,24,27,30)$. 
P. pachyrhizi isolates from two earlier studies, one completed based on isolates collected in Nigeria (30) and the other based on U.S. isolates (27), were also used in the current study. In Nigeria, 116 isolates were categorized into seven pathotype groups based on the number of sporulating uredinia per square centimeter on soybean genotypes with the resistance genes Rppl to -4 and two susceptible soybean genotypes. In the United States, 72 isolates were classified into three pathotypes and six aggressiveness groups based on their virulence and number of sporulating uredinia per square centimeter on eight soybean genotypes. In the current study, our objective was to assess aggressiveness among $P$. pachyrhizi isolates collected from Nigeria and the United States by measuring six quantitative traits using two soybean genotypes, one genotype produced a TAN susceptible reaction and the other that produced an RB incomplete resistance reaction to all the isolates. Selection for these quantitative traits may influence pathogen evolution in agricultural pathosystems, which could result in differential adaption of the pathogen to host plant cultivars (22).

\section{Materials and Methods}

Isolate collection, purification, and multiplication. In total, 116 and 72 isolates of P. pachyrhizi from Nigeria and the United States, respectively, were used in this study. These isolates were collected from soybean in Nigeria in 2005 and from soybean and kudzu in the United States from 2006 to 2009. To establish cultures of $P$. pachyrhizi, urediniospores (approximately $0.5 \mathrm{mg}$ ) were harvested from two to six soybean or kudzu leaf samples collected from each location. These spores were used to inoculate the abaxial surface of soybean genotypes 'TGx 1485-1D' or 'Williams 82' leaf pieces $(26,29)$. When sporulation occurred, single-spore isolates were obtained following a previously described procedure (26). To increase inoculum, isolates were multiplied on detached leaves of TGx 1485-1D or Williams 82 to produce an adequate quantity of urediniospores for the experiments.

Plant material. Two soybean genotypes, plant introduction (PI) 462312 and TGx 1485-1D, were selected for this study based on their disease reaction; PI 462312 produced an RB reaction type while TGx 1485-1D produced a TAN reaction type when inoculated with Nigerian or U.S. $P$. pachyrhizi isolates $(27,30)$. The resistance in PI 462312 (Ankur) (Rpp3) was reported in 1983 (9) and, to our knowledge, has not been deployed in Nigeria or the United States.

Pathogen aggressiveness. In Nigeria, plants of each of the two soybean genotypes were planted every 2 weeks in the greenhouse under rust-free conditions for a constant supply of 2- to 3-week-old trifoliolate leaves for inoculation. Excised leaflets were rinsed in three to six changes of sterile distilled water and the abaxial side was sprayed with a spore suspension of $150 \mu \mathrm{l}\left(1 \times 10^{5}\right.$ spores $/ \mathrm{ml}$ of water) per leaflet using an atomizer attached to an air compressor. A single leaf piece (approximately 3 by $4 \mathrm{~cm}$ ) was carefully placed in a 9-cm-diameter petri dish with adaxial side appressed on $1 \%$ agar amended with kinetin at $10 \mu \mathrm{g} / \mathrm{ml}$. Petri dishes containing leaf pieces (three dishes for each isolate-genotype combination) were then incubated at $20^{\circ} \mathrm{C}$ with a cycle of $12 \mathrm{~h}$ each of light and darkness $(29,30)$.

In the United States, plants of each of the two genotypes planted every 2 weeks were placed inside a growth chamber (Percival Scientific, Inc.) maintained at 65 to $75 \%$ relative humidity with a cycle of 14 and $10 \mathrm{~h}$ of light and darkness, respectively, set at 23 to $25^{\circ} \mathrm{C}$. Leaf pieces were excised from plants in the chamber after being rinsed in three to six changes of sterile distilled water, and their abaxial surface was sprayed as previously described (27). Briefly, inoculated leaf sections (approximately 3 by $4 \mathrm{~cm}$ each) were carefully placed adaxial side down on 9-cm-diameter filter papers (Whatman International Ltd.) in 9-cm petri dishes. Sterile filter papers (two per dish) were saturated with sterile distilled water prior to placing leaf sections in dishes. Petri dishes with leaf sections (a leaf section per dish and three replicate dishes for each isolate-genotype combination) were incubated in the dark for a period of $12 \mathrm{~h}$ followed by a cycle of $14 \mathrm{~h}$ of light $(380 \mu \mathrm{mol}$ PAR) and $10 \mathrm{~h}$ of darkness inside a tissue chamber (Percival Scientific, Inc.) maintained at $23^{\circ} \mathrm{C}$. Prior to incubation, dishes were placed inside zip bags (Webster Industries) (27).

In both experiments, inoculated leaf pieces were observed daily starting at 3 days after inoculation up to 17 days after inoculation using a dissecting microscope at $\times 20$ magnification. The number of days after inoculation to first appearance of lesions, uredinia, and sporulation, along with the number of lesions and sporulating uredinia per square centimeter of leaf tissue and the number of uredinia per lesion, were recorded 17 days after inoculation. Both experiments were completed twice.

Data analyses. Data from both runs of each experiment were first tested for homogeneity of error variance among experimental factors using Bartlett's test in SAS (version 9.2; SAS Institute Inc.). Homogeneity of variance testing was not significant $(P>$ $0.05)$ and data from runs were pooled together for subsequent statistical analyses.

The number of lesions and sporulating uredinia per square centimeter and the uredinia per lesion for each genotype and each isolate combination were analyzed using PROC UNIVARIATE in SAS. From these analyses, three quantitative trait classes were defined for the numbers of lesions and sporulating uredinia per square centimeter and the uredinia per lesion for each host genotype and isolate combination. The first class consisted of means in the first quartile (two standard deviations below the mean [-2 SD]), the second class consisted of means in second and third quartiles (from $-1 \mathrm{SD}$ to $+1 \mathrm{SD}$ from the mean), and the third class consisted of means in the fourth quartile (+2 SD). The percentage of isolates in each class was determined for each country and their regions $(26,30)$, and differences in distribution of isolates in three individual classes between the Nigerian and U.S. isolates were tested based on Fisher's exact test option using PROC FREQ in SAS.

To determine the relationship between the number of lesions and the number of sporulating uredinia per unit leaf area, 72 isolates from United States and Nigeria were used to inoculate PI 462312 and TGx 1485-1D. The 72 isolates from Nigeria used in this part of the study were randomly selected from the original set of 116 isolates. Correlation analysis was used to determine the relationship between number of lesions, number of sporulating uredinia, and number of uredinia per lesion on PI 462312 and TGx 1485-1D based on Nigerian and U.S. isolates used in the study. The number of sporulating uredinia was regressed to the number of lesions per square centimeter of leaf tissue separately for each host genotype and each set of isolates using PROC REG in SAS, and the paired $t$ test procedure of SAS was used to determine significant differences in the slopes of the regression lines.

\section{Results}

Aggressiveness of $P$. pachyrhizi isolates from Nigeria and the United States. Significant differences $(P<0.001)$ were observed for all the quantitative traits on either PI 462312 or TGx 1485-1D following their inoculation with $P$. pachyrhizi isolates from Nigeria and the United States The number of days after inoculation to first appearance of lesions, uredinia, and sporulation was greater on PI 462312 than on TGx 1485-1D when inoculated with isolates from each country (Table 1). For example, it took fewer days for first appearance of lesions, uredinia, and sporulation on PI 462312 when inoculated with isolates from the United States compared with isolates from Nigeria but there was no significant difference in number of days to first appearance for these three variables on TGx 1485-1D (Table 1).

The numbers of lesions and sporulating uredinia per square centimeter of leaf tissue were lower on PI 462312 than on TGx 14851D when inoculated with isolates from both countries (Table 1). No significant differences were observed in these two traits when host genotypes were inoculated with isolates from either Nigeria or the United States, except for sporulating uredinia, which was higher on TGx 1485-1D when inoculated with isolates from Nigeria than when inoculated with isolates from the United States. The number of uredinia per lesion was lower on PI 462312 than on 
TGx 1485-1D when inoculated with isolates from each country. However, uredinia per lesion on each host genotype were generally similar regardless of whether the host genotypes were inoculated with isolates from Nigeria or the United States (Table 1).

There was a significant difference $\left(P<0.001, \chi^{2}>10\right)$ in the distribution of Nigerian and U.S. isolates in the three quantitative trait classes based on number of lesions and sporulating lesions per square centimeter of leaf tissue and number of uredinia per lesion on the two soybean genotypes, except for number of sporulating uredinia on PI 462312 (Fig. 1). The proportion of isolates in class I was greater for U.S. than Nigerian isolates on either PI 462312 or TGx 1485-1D for all traits, except for the number of uredinia per

Table 1. Mean ( \pm standard deviation) of six quantitative traits used to evaluate isolate aggressiveness of 116 and 72 Phakopsora pachyrhizi isolates collected from Nigeria and the United States, respectively, after controlled inoculation of two soybean genotypes

\begin{tabular}{|c|c|c|c|c|c|c|c|}
\hline \multirow[b]{2}{*}{ Isolate origin } & \multirow[b]{2}{*}{ Genotype } & \multicolumn{3}{|c|}{ Days after inoculation ${ }^{a}$} & \multicolumn{2}{|c|}{ Number/cm² } & \multirow[b]{2}{*}{ Uredinia/lesion $^{c}$} \\
\hline & & Lesions & Uredinia & Sporulation & Lesions $^{b}$ & Sporulation $^{b}$ & \\
\hline \multirow[t]{2}{*}{ Nigeria } & PI 462312 & $7.7 \pm 0.5$ & $12.4 \pm 0.6$ & $14.8 \pm 0.6$ & $6.7 \pm 2.9$ & $6.7 \pm 5.0$ & $0.9 \pm 0.5$ \\
\hline & TGx 1845-1D & $5.3 \pm 0.5$ & $7.5 \pm 0.6$ & $9.8 \pm 0.9$ & $19.5 \pm 5.4$ & $54.0 \pm 15.1$ & $2.8 \pm 0.6$ \\
\hline \multirow[t]{2}{*}{ United States } & PI 462312 & $6.2 \pm 0.4$ & $10.2 \pm 0.8$ & $12.4 \pm 0.7$ & $5.5 \pm 3.0$ & $6.7 \pm 5.3$ & $1.1 \pm 0.5$ \\
\hline & TGx 1845-1D & $5.1 \pm 0.3$ & $7.2 \pm 0.4$ & $9.2 \pm 0.4$ & $13.6 \pm 4.7$ & $28.5 \pm 10.4$ & $2.1 \pm 0.3$ \\
\hline
\end{tabular}

a Shortest number of days to lesion appearance, uredinia formation, and sporulation of uredinia.

b Number of lesions and sporulation of uredinia counted per square centimeter recorded 17 days after inoculation.

${ }^{\mathrm{c}}$ Calculated from the 17 th day after inoculation counts.
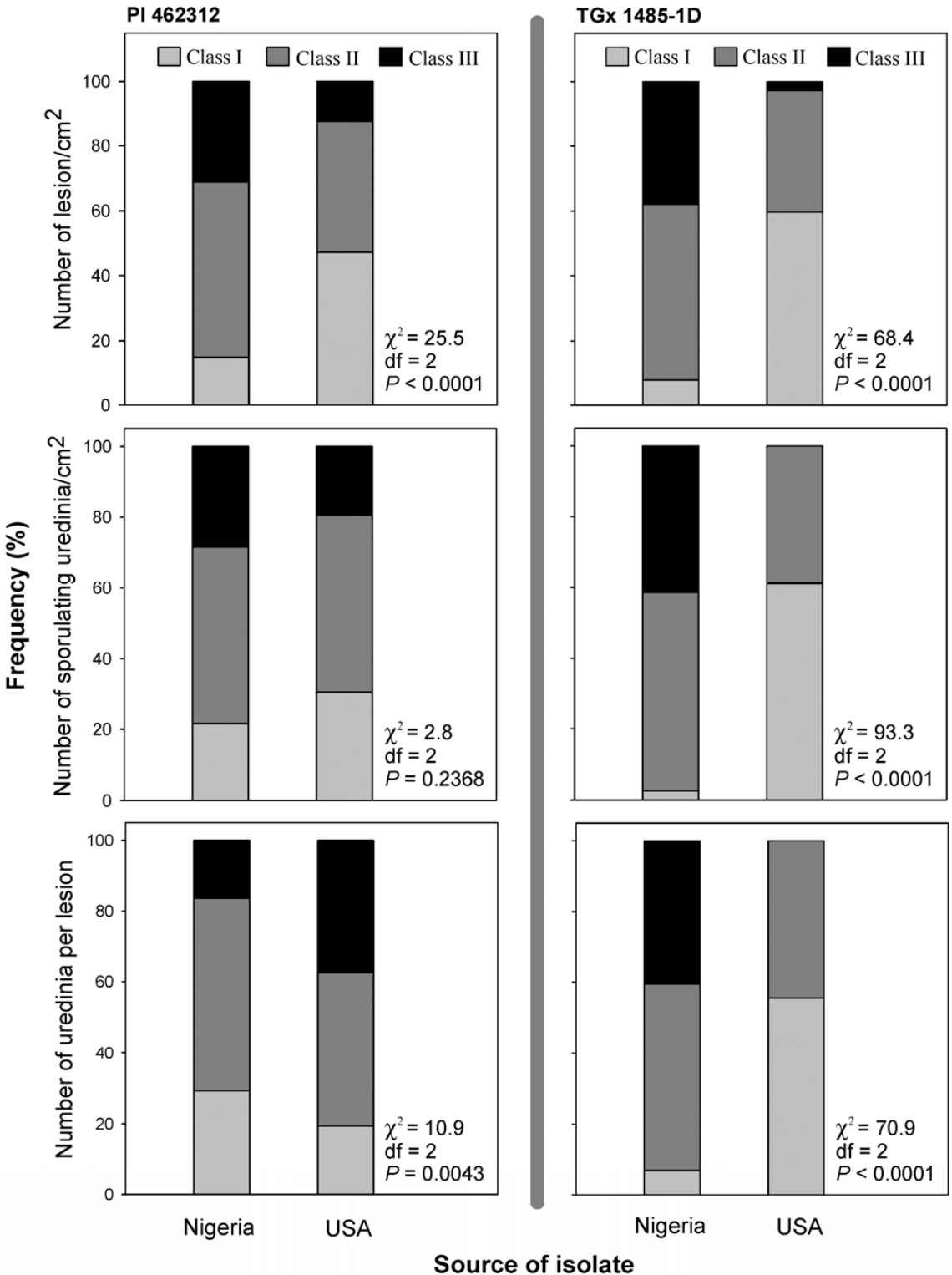

Fig. 1. Proportion of Phakopsora pachyrhizi isolates (\%) in three quantitative trait classes, with the first class consisting of means in the first quartile (two standard deviations below the mean [ -2 SD]), the second class consisting of means in second and third quartiles (from -1 SD to +1 SD from the mean), and the third class consisting of means in the fourth quartile ( $+2 \mathrm{SD}$ ) based on the distribution of the number of lesions and the number of sporulating uredinia per square centimeter of leaf tissue and the number of lesions per uredinia 17 days after inoculation on soybean genotypes PI 462312 and TGx 1485-1D with 116 and 72 isolates from Nigeria and the United States, respectively. The distribution of isolates in individual quantitative trait classes was compared based on records of traits on host genotypes inoculated with isolates from Nigeria and the United States using a $\chi^{2}$ test. 
lesion on PI 462312. The proportion of isolates in class III for number of lesions was higher for Nigerian (31 and 38\%) than U.S. (13 and 3\%) isolates on PI 462312 and TGx 1485-1D, respectively. The proportion of isolates in class III for number of sporulating uredinia was higher for Nigerian (28 and 41\%) than U.S. (19 and $0 \%$ ) isolates on PI 462312 and TGx 1485-1D, respectively. The proportion of isolates in class III for number of uredinia per lesion was higher for Nigerian isolates $(41 \%)$ than U.S. isolates $(0 \%)$ on TGx 1485-1D but lower on PI 462312, on which the proportion of U.S. isolates was higher $(38 \%)$ than that of the Nigerian isolates $(16 \%)$.

Fisher's exact test analysis showed significant differences $(P<$ $0.05)$ in the distribution of isolates in the quantitative trait classes between agroecological zones in Nigeria or geographical regions in the United States (Table 2). For example, the Derived Savanna in Nigeria had the highest proportion of isolates in class III (15 and $25 \%$ for PI 462312 and TGx 1485-1D, respectively) compared with other agroecological zones. In the United States, a significant $(P<0.05)$ difference in the distribution of isolates between geographical regions was observed only on TGx 1485-1D, with the South region accounting for highest proportion in class II (28\%).

Relationship between number of lesions and uredinia per lesion for specific rust isolates. A linear regression equation significantly $(P<0.05)$ described the relationship between number of lesions and number of uredinia per square centimeter of leaf tissue when host genotypes were inoculated with isolates from either the United States or Nigeria. For example, the regression equation explained 70 and $81 \%$ of the total variance when PI 462312 was inoculated with isolates from Nigeria and United States, respectively (Fig. 2A). The corresponding values of coefficient of determination when TGx 1485-1D was inoculated with isolates from Nigeria and the United States were 81 and $80 \%$, respectively (Fig. 2B). A paired $t$ test indicated that slopes for the regression line between number of lesions and number of uredinia per square centimeter of leaf tissue were not significantly different $(P>0.0675)$ when PI 462312 was inoculated by isolates from Nigeria and the United States. However, significant differences $(P<0.0001)$ between the slopes of the regression lines were observed when TGx 1485-1D was inoculated by isolates from the two countries.

Despite different reaction types for the two soybean genotypes, significant positive correlations occurred between number of lesions on PI 462312 and TGx 1485-1D when inoculated with isolates from Nigeria $(r=0.34, P<0.0001)$ and the United States $(r=$ $0.57, P<0.0001$ ) (Table 3). Similarly, significant positive correlations were observed between number of sporulating uredinia on PI
462312 and TGx 1485-1D inoculated with isolates from Nigeria $(r$ $=0.43, P<0.0001)$ and the United States $(r=0.50, P<0.0001)$. Correlations between number of uredinia per lesion on PI 462312 and TGx 1485-1D were significant when inoculated with isolates from Nigeria ( $r=0.40, P<0.0001)$ but not significant with isolates from the United States (Table 3).

\section{Discussion}

The use of quantitative measurements such as infection efficiency, latent period, spore production rate, infectious period, and lesion size to address aggressiveness in plant pathogens has been reviewed (21). In our study, the aggressiveness of $P$. pachyrhizi isolates in Nigeria and the United States showed significant differences in days to first appearance of lesions, uredinia, sporulation, and number of lesions and sporulating uredinia per square centimeter leaf tissue, and the number of uredinia per lesion.

Infection efficiency, which is measured as a percentage of successful infections from a controlled number of deposited spores (22), was not directly measured in our study. Rather, we quantified infection efficiency indirectly using number of lesions per square centimeter of leaf tissue. Lesion numbers were dependent on the soybean genotype, with fewer lesions forming on the incomplete resistance genotype PI 462312 compared with the susceptible genotype TGx 1485-1D, regardless of the origin of the isolates. For $P$. pachyrhizi, infection efficiency includes fungal penetration and colonization of host tissue, which could affect any indirect measurements like lesion counts. A recent study on characterization of fungal colonization in soybean genotypes showed that the infection process of $P$. pachyrhizi was similar in both compatible (TAN, susceptible) and incompatible (RB, incomplete resistance) soybean genotypes up to 2 days after inoculation; however, differences were observed after 2 days following inoculation where a genotype with a TAN reaction had more hyphae in the mesophyll tissue compared with genotypes with an RB reaction (32). In another study, infection efficiency based on the number of lesions per square centimeter of leaf tissue was effective in showing differences in aggressiveness among $P$. triticina isolates on wheat (22). Infection efficiency may not be a useful trait to measure $P$. pachyrhizi isolates if it is based on spore germination and penetration. However, it may be a useful trait if measured indirectly either as colonization based on quantification of fungal DNA or lesions per leaf area of tissue.

Latent period, measured as the first appearance of spores (22), was up to 4 days longer in PI 462312 than TGx 1485-1D, indicating that latent period is an important component of resistance. Any delay in sporulation would affect an epidemic and likely delay or

Table 2. Proportion of Phakopsora pachyrhizi isolates (\%) from four agroecological zones in Nigeria and three regions of United States classified in three quantitative trait classes based on the number of sporulating uredinia following inoculation of two soybean genotypes ${ }^{\mathrm{a}}$

\begin{tabular}{|c|c|c|c|c|c|c|c|c|c|}
\hline \multirow[b]{3}{*}{ Country, region ${ }^{\mathrm{b}}$} & \multirow[b]{3}{*}{$N^{\mathrm{c}}$} & \multicolumn{8}{|c|}{ Soybean genotype } \\
\hline & & \multicolumn{4}{|c|}{ PI 462312} & \multicolumn{4}{|c|}{ TGx 1485-1D } \\
\hline & & $\mathbf{I}$ & II & III & $P$ & $\mathbf{I}$ & II & III & $P$ \\
\hline \multicolumn{10}{|l|}{ Nigeria } \\
\hline DS & 52 & 8 & 22 & 15 & $\ldots$ & 0 & 20 & 25 & $\ldots$ \\
\hline $\mathrm{HF}$ & 3 & 1 & 2 & 0 & $\ldots$ & 0 & 3 & 0 & $\ldots$ \\
\hline NGS & 35 & 12 & 13 & 5 & $\ldots$ & 2 & 23 & 5 & $\ldots$ \\
\hline SGS & 26 & 1 & 13 & 9 & $\ldots$ & 1 & 10 & 11 & $\ldots$ \\
\hline Fisher's exact test $\mathrm{t}^{\mathrm{d}}$ & $\ldots$ & $\ldots$ & $\ldots$ & $\ldots$ & $<0.0340$ & $\ldots$ & $\ldots$ & $\ldots$ & $<0.0026$ \\
\hline United States & & & & & & & & & $\ldots$ \\
\hline Central & 10 & 3 & 11 & 0 & $\ldots$ & 10 & 4 & 0 & $\ldots$ \\
\hline South & 41 & 18 & 25 & 14 & $\ldots$ & 29 & 28 & 0 & $\ldots$ \\
\hline Southeast & 21 & 10 & 14 & 6 & $\ldots$ & 22 & 7 & 0 & $\ldots$ \\
\hline Fisher's exact test & $\ldots$ & $\ldots$ & $\ldots$ & $\ldots$ & $=0.1492$ & $\ldots$ & $\ldots$ & $\ldots$ & $<0.05$ \\
\hline
\end{tabular}

a Three quantitative trait classes: $\mathrm{I}=$ means in the first quartile (two standard deviations below the mean or $-2 \mathrm{SD}$ ), $\mathrm{II}=$ means in second and third quartiles (from $-1 \mathrm{SD}$ to $+1 \mathrm{SD}$ from the mean), and III = means in the fourth quartile $(+2 \mathrm{SD})$ based on the distribution of the number of sporulating uredinia per square centimeter of leaf tissue 17 days after inoculation of soybean genotypes PI 462312 and TGx 1485-1D with isolates from Nigeria and the United States.

${ }^{\mathrm{b}}$ Nigeria agroecological zones = Derived savanna (DS), Humid Forest (HF), Northern Guinea savanna (NGS), and Southern Guinea savanna (SGS) (30); U.S. regions from Twizeyimana and Hartmann (27).

${ }^{\mathrm{c}}$ Number of isolates.

${ }^{\mathrm{d}}$ Differences in the quantitative trait classes within zones in Nigeria or regions in the United States. 
shift the pattern of disease progress (34). When comparing the isolates from Nigeria with those from the United States, the latent period was longer for the Nigerian isolates than the U.S. isolates on PI 462312 but not on the susceptible TGx 1485-1D. Other reports have shown that isolates with shorter latent periods were more aggressive than isolates that have longer latent periods $(25,34)$. The influence of the host genotype and whether it is susceptible or resistant influences the length of the latent period as observed in our study and, thus, needs to be considered when determining aggressiveness of $P$. pachyrhizi isolates.

Spore production (or sporulation rate) is often measured as spores per lesion or spores per unit (22). In this study, sporulation was measured as number of sporulating uredinia per square centimeter of leaf tissue and was lower for PI 462312 than for TGx 1485-1D regardless of isolate, indicating that this trait is an im-

\section{A PI 462312}

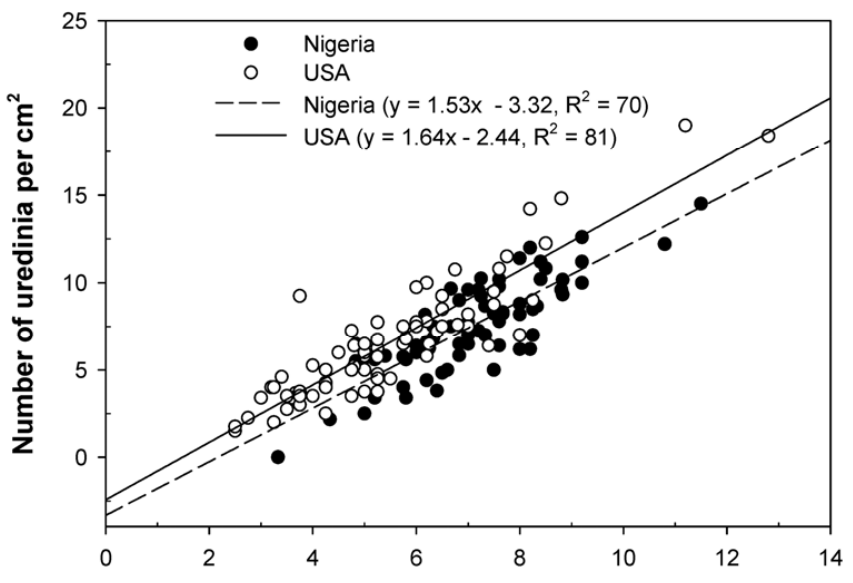

B TGx 1485-1D

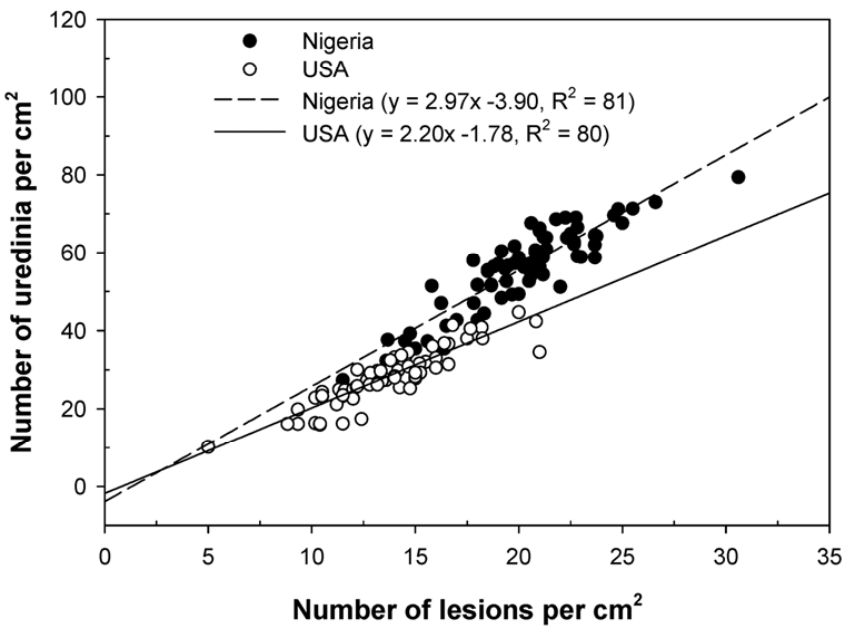

Fig. 2. Relationship between the number of lesions and the number of sporulating uredinia per square centimeter of leaf tissue recorded 17 days after inoculation on soybean genotypes A, PI 462312 (resistant) and B, TGx 1485-1D (susceptible) inoculated with Phakopsora pachyrhizi isolates collected from Nigeria and the United States. portant component of resistance. The sporulation rate was not quantified because of the large number of isolates used in our study.

Other traits that have been suggested to quantify aggressiveness of a pathogen or isolate, such as infectious period and lesion size (22), were not measured in this study. Infectious period, which is the time from the start to the end of sporulation, is another difficult trait to measure when examining many isolates of $P$. pachyrhizi, because it requires removing spores from uredinia until the end of spore production. This process can be longer than 40 days, as has been reported in some cereal rusts (22). Lesion size, which is defined as the surface area that produces spores (22), also was not measured but it may be an important trait when evaluating aggressiveness of $P$. pachyrhizi, especially in cases where the lesion size may be expanding or an epidemic is occurring and new lesions continue to develop.

The wide range of variation in the aggressiveness components observed in $P$. pachyrhizi isolates from Nigeria and the United States is likely to be due to a number of factors. Some of these factors could include effects of weather variables (e.g., temperature), as suggested in studies on Puccinia striiformis f. sp. tritici, where new isolates were shown to be more adapted and more aggressive at warmer temperatures than the older isolates (19). Others studies have suggested environment-genotype interactions (11) and host physiological status as factors that could interact with and influence pathogen aggressiveness $(11,22)$. In Nigeria, more isolates with a higher number of sporulating uredinia on PI 462312 or TGx1485-1D originated from the Derived Savanna agroecological zone, a region where weather conditions (higher yearly rainfall and moderate temperatures of 25 to $30^{\circ} \mathrm{C}$ ) are conducive to $P$. pachyrhizi infection (30). Similarly, in the United States, the South region accounted for a higher number of isolates with greater numbers of sporulating uredinia on PI 462312 or TGx1485-1D. Many areas in the southern United States are characterized by weather conditions that favor soybean rust infection and where $P$. pachyrhizi spores also overwinter on kudzu plants (26).

In summary, U.S. isolates of $P$. pachyrhizi had shorter days to lesion appearance, uredinia formation, and uredinia eruption than Nigerian isolates, indicating that, at least for these traits, the U.S. isolates were more aggressive than the Nigerian isolates when examined on the susceptible soybean genotype TGx 1485-1D. However, the U.S. isolates had fewer numbers of lesions and uredinia per leaf tissue and uredinia per lesion than Nigerian isolates, indicating that, at least for these traits, the Nigerian isolates were more aggressive than the U.S. isolates. By defining and understanding the traits used to measure aggressiveness, meaningful comparisons can be made to understand what factors, such as environment and genotype differences, play a role in determining the quantitative aspects of aggressiveness.

\section{Acknowledgments}

We thank the United Soybean Board for partial financial support.

\section{Literature Cited}

1. Andrivon, D. 1993. Nomenclature for pathogenicity and virulence: The need for precision. Phytopathology 83:889-890.

2. Bonde, M. R., Nester, S. E., Austin, C. N., Stone, C. L., Frederick, R. D., Hartman, G. L., and Miles, M. R. 2006. Evaluation of virulence of Phakopsora pachyrhizi and P. meibomiae isolates. Plant Dis. 90:708-716.

3. Bromfield, K. R., Melching, J. S., and Kingsolver, C. H. 1980. Virulence

Table 3. Pearson correlation coefficients for number of lesions, number of sporulating uredinia, and number of uredinia per lesion on two soybean genotypes (PI 462312 and TGx 1485-1D) counted 17 days after inoculation with Phakopsora pachyrhizi isolates collected from Nigeria and the United States ${ }^{\mathrm{a}}$

\begin{tabular}{llr}
\hline & & \multicolumn{2}{c}{ Correlation coefficient } \\
\cline { 2 - 4 } Variable & Nigerian isolates & United States isolates \\
\hline Number of lesions per square centimeter & $0.34(P<0.0001)$ & $0.57(P<0.0001)$ \\
Number of uredinia per square centimeter & $0.43(P<0.0001)$ & $0.50(P<0.0001)$ \\
Number of uredinia per lesion & $0.3982(P<0.0001)$ & $0.11(P=0.3321)$ \\
\hline
\end{tabular}

${ }^{a}$ PI 462312 = a plant introduction that produced red-brown lesions, indicating an incomplete resistant reaction to all the isolates; and TGx $1485-1 \mathrm{D}=\mathrm{a}$ breeding line that produced tan lesions, indicating a susceptible reaction to all the isolates. 
and aggressiveness of Phakopsora pachyrhizi isolates causing soybean rust. Phytopathology 70:17-21.

4. Burdon, J. J., and Lenne, J. 1989. The Phakopsora pachyrhizi-Kennedia rubicunda host-pathogen association and its relation to leaf rust of Glycine spp. Aust. J. Agric. Res. 40:265-272.

5. Burdon, J. J., and Speer, S. S. 1984. A set of differential Glycine hosts for the identification of races of Phakopsora pachyrhizi Syd. Euphytica 33:891896.

6. Díaz Arias, M. M., Leandro, L. F., and Munkvold, G. P. 2013. Aggressiveness of Fusarium species and impact of root infection on growth and yield of soybean. Phytopathology 103:822-832.

7. Hartman, G. L., Hill, C. B., Twizeyimana, M., Miles, M. R., and Bandyopadhyay, R. 2011. Interaction of soybean and Phakopsora pachyrhizi, the cause of soybean rust. CAB Reviews: Perspectives in Agriculture, Veterinary Science, Nutrition and Natural Resources 6. doi:10.1079/ PAVSNNR20116025

8. Hartman, G. L., Wang, T. C., and Tschanz, A. T. 1991. Soybean rust development and the quantitative relationship between rust severity and soybean yield. Plant Dis. 75:596-600.

9. Hartwig, E. E., and Bromfield, K. R. 1983. Relationships among three genes conferring specific resistance to rust in soybeans. Crop Sci. 23:237239.

10. Kull, L. S., Pedersen, W. L., and Hartman, G. L. 2004. Mycelial compatibility and aggressiveness of Sclerotinia sclerotiorum. Plant Dis. 88:325-332.

11. Lannou, C. 2012. Variation and selection of quantitative traits in plant pathogens. Annu. Rev. Phytopathol. 50:319-338.

12. Levy, C. 2005. Epidemiology and chemical control of soybean rust in Southern Africa. Plant Dis. 89:669-774.

13. Li, S., Hartman, G. L., and Boykin, D. L. 2010. Aggressiveness of Phomopsis longicolla and other Phomopsis spp. on soybean. Plant Dis. 94:10351040.

14. Li, S., Hartman, G. L., and Chen, Y. 2009. Evaluation of aggressiveness of Fusarium virguliforme isolates that cause sudden death syndrome. J. Plant Pathol. 91:77-86.

15. Lin, S. Y. 1966. Studies on the physiologic races of soybean rust fungus, Phakopsora pachyrhizi Syd. J. Taiwan Agric. Res. 15:24-28.

16. McLean, R. J., and Byth, D. E. 1980. Inheritance of resistance to rust (Phakopsora pachyrhizi) in soybeans. Aust. J. Agric. Res. 31:951-956.

17. Melching, J. S., Bromfield, K. R., and Kingsolver, C. H. 1979. Infection, colonization, and uredospore production on Wayne soybean by four cultures of Phakopsora pachyrhizi, the cause of soybean rust. Phytopathology 69:1262-1265.

18. Miles, M. R., Levy, C., Morel, W., Mueller, T., Steinlage, T., van Rij, N., Frederick, R. D., and Hartman, G. L. 2007. International fungicide efficacy trials for the management of soybean rust. Plant Dis. 91:1450-1458.

19. Milus, E. A., Seyran, E., and McNew, R. 2006. Aggressiveness of Puccinia striiformis f. sp. tritici isolates in the south-central United States. Plant Dis. 90:847-852.

20. Mueller, T. A., Miles, M. R., Morel, W., Marios, J. J., Wright, D. L., Kemerait, R. C., Levy, C., and Hartman, G. L. 2009. Effect of fungicide and timing of application on soybean rust severity and yield. Plant Dis. 93:243248.

21. Pariaud, B., Ravigne, V., Halkett, F., Goyeau, H., Carlier, J., and Lannou, C. 2009. Aggressiveness and its role in the adaptation of plant pathogens. Plant Pathol. 58:409-424.

22. Pariaud, B., Robert, C., Goyeau, H., and Lannou, C. 2009. Aggressiveness components and adaptation to a host cultivar in wheat leaf rust. Phytopathology 99:869-878.

23. Paul, C., and Hartman, G. L. 2009. Sources of soybean rust resistance challenged with single-spored isolates of Phakopsora pachyrhizi collected from the USA. Crop Sci. 49:1781-1785.

24. Pham, T. A., Miles, M. R., Frederick, R. D., Hill, C. B., and Hartman, G. L. 2009. Differential responses of resistant soybean genotypes to ten isolates of Phakopsora pachyrhizi. Plant Dis. 93:224-228.

25. Rapilly, F. 1979. Yellow rust epidemiology. Annu. Rev. Phytopathol. 17:5973.

26. Twizeyimana, M., and Hartman, G. L. 2010. Culturing Phakopsora pachyrhizi on detached leaves and urediniospore survival at different temperatures and relative humidities. Plant Dis. 94:1453-1460.

27. Twizeyimana, M., and Hartman, G. L. 2012. Pathogenic variation of Phakopsora pachyrhizi isolates on soybean in the United States from 2006 to 2009. Plant Dis. 95:75-81.

28. Twizeyimana, M., Ojiambo, P. S., Hartman, G. L., and Bandyopadhyay, R. 2011. Dynamics of soybean rust epidemics in sequential plantings of soybean cultivars in Nigeria. Plant Dis. 95:43-50.

29. Twizeyimana, M., Ojiambo, P. S., Ikotun, T., Paul, C., Hartman, G. L., and Bandyopadhyay, R. 2007. Comparison of field, greenhouse, and detachedleaf evaluations of soybean germplasm for resistance to Phakopsora pachyrhizi. Plant Dis. 91:1161-1169.

30. Twizeyimana, M., Ojiambo, P. S., Sonder, K., Ikotun, T., Hartman, G. L., and Bandyopadhyay, R. 2009. Pathogenic variation of Phakopsora pachyrhizi infecting soybean in Nigeria. Phytopathology 99:353-361.

31. Van der Plank, J. 1968. Disease Resistance in Plants. Academic Press, London, New York.

32. Vittal, R., Paul, C., Hill, C. B., and Hartman, G. L. 2014. Characterization and quantification of fungal colonization of Phakopsora pachyrhizi in soybean genotypes. Phytopathology 104:86-94.

33. Yamaoka, Y., Fujiwars, Y., Kakishima, M., Katsuya, K., and Yamada, K. 2002. Pathogenic races of Phakopsora pachyrhizi on soybean and wild host plants collected in Japan. J. Gen. Plant Pathol. 68:52-56.

34. Zadoks, J. C. 1961. Yellow rust on wheat: Studies in epidemiology and physiologic specialization. Tijdschr. Plantenziekten 67:69-259. 